\title{
Notes liminaires
}

\section{Adrien Pouliot}

Volume 37, 1970

La vie religieuse au Manitoba

URI : https://id.erudit.org/iderudit/1007271ar

DOI : https://doi.org/10.7202/1007271ar

Aller au sommaire du numéro

Éditeur(s)

Les Éditions Historia Ecclesiæ Catholicæ Canadensis Inc.

ISSN

0318-6172 (imprimé)

1927-7067 (numérique)

Découvrir la revue

Citer ce document

Pouliot, A. (1970). Notes liminaires. Sessions d'étude - Société canadienne

d'histoire de l'Église catholique, 37, xiii-xiii. https://doi.org/10.7202/1007271ar

Tous droits réservés @ Les Éditions Historia Ecclesiæ Catholicæ Canadensis Inc., 1972
Ce document est protégé par la loi sur le droit d'auteur. L'utilisation des services d'Érudit (y compris la reproduction) est assujettie à sa politique d'utilisation que vous pouvez consulter en ligne.

https://apropos.erudit.org/fr/usagers/politique-dutilisation/ 


\section{Notes liminaires}

1. Parce qu'il était impossible de publier tous les travaux, vous ne trouverez ici ni les « essais ", malgré leur mérite et leur intérêt, ni les études parues ailleurs: Bernard Pénisson, "L'image de la France catholique d'après La Liberté, hebdomadaire manitobain, 1913-1920 » (voir: Revue d'histoire de l'Amérique française, vol. XXV, $\mathrm{n}^{\circ} 1$ [juin 1971], pp. 3 à 37) ; René Hardy, "L'activité sociale du curé de Notre-Dame-deQuébec: aperçu de l'influence du clergé au milieu du XIX ${ }^{\bullet}$ siècle * (voir: Histoire sociale, publication conjointe de l'Université d'Ottawa et de Carleton University, ${ }^{\circ} 6$ [novembre 1970], pp. 5-32) ; Léo Beaulieu, « L'évolution du concept d'action catholique, de 1945 à nos jours» (voir Les Cloches de Saint-Boniface, vol. LXIX, $n^{0} 6$ [juillet-août], pp. 231-243. A la page 235, $9^{\mathrm{e}}$ ligne, il faut lire: de Lambeth, à Londres, au lieu de: d'Upsala, en Suède).

2. Un de nos directeurs honoraires, $\mathrm{M}^{\mathrm{gr}}$ Maurice O'Bready, de Sherbrooke, est décédé le 10 juillet 1970, à l'âge de 69 ans. Membre de la Société depuis 1940, directeur en 1963, président de la section française de 1965 à 1967, président général en 1967-1968, $\mathrm{M}^{\mathrm{gr}}$ O'Bready fut, dans son patelin des Cantons de l'Est, un éducateur de grande classe et l'histoire fut, entre ses mains, un instrument efficace. C'est lui qui organisa, en juin 1966, le congrès tenu à l'Université de Sherbrooke, conjointement avec les Sociétés savantes. Il y révéla, un soir, le secret de son succès et, du coup, nous apprit le moyen de susciter une relève: - Pour aboutir à quelque chose, il faut être un enragé de ce que l'on entreprend ! 》 Humaniste et prêtre, $\mathbf{M}^{\text {gr }} 0^{\prime}$ Bready s'est appliqué à rendre à la double société - civile et religieuse — dont il fut membre le témoignage unique d'un actif et intelligent amour.

3. S'adressant à l'Action catholique du monde entier, le 10 janvier 1960, le pape Jean XXIII définissait ainsi le sens de l'Église : "Cet œil surnaturel qui scrute les institutions, les faits, l'histoire, pour y découvrir l'œuvre de Dieu et vivre dans cette lumière. »

L'histoire religieuse du Manitoba, que des spécialistes vont nous détailler, a d'abord été vécue comme une collaboration des humains à l'exécution du plan divin de la Rédemption. Depuis les Actes des Apôtres, c'est le rôle de l'histoire de l'Église de faciliter aux chrétiens, de génération en génération, l'intelligence des voies de Dieu, pour y ajuster leurs options, jauger les vraies valeurs, choisir les vrais moyens, vivre en pleine lumière évangélique. Que l'analyse des " actes des apôtres du Manitoba " - évêques, prêtres, religieux, laïcs - nous aide tous à collaborer à notre tour avec le Maître de l'Histoire, pour l'édification d'un Canada de plus en plus chrétien.

Québec, le 1er juin 1971.

Adrien Pouliot, s.j., président de la section. 